\title{
Developing Literacy Research in Sápmi
}

\author{
Hanna Outakoski
}

\begin{abstract}
Literacy research is the field of study that is interested in writing and reading, and in all activities, contexts, and ideas that are connected to texts, their production and interpretation. Within this field, several studies have been conducted in Indigenous multilingual contexts, but only a few of such studies mention Indigenous research and its principles. More importantly, explicit Indigenous methodologies are still absent from literacy studies, making it difficult to reflect upon methodological choices. Based on a comparative study of two literacy projects conducted in an Indigenous Sámi context, this chapter suggests that a first step toward the implementation of Indigenous methodologies is an awareness of Indigenous research principles. Awareness of the principles is required before they can be respected and followed, and before new methodologies can be discussed. This chapter suggests that it is also possible to consciously move towards methodologies that align with Indigenous research principles in literacy studies. In the best case, careful consideration of methodologies and guiding principles can lead to an understanding of the literacy landscape from unique perspectives that follow from collaboration, inclusion and mutual respect.
\end{abstract}

\section{Keywords}

Indigenous methodologies - Sámi literacy - educational literacy studies

\section{1 \\ Introduction}

This chapter paves the way for new collaborative approaches within educational literacy research, and discusses the methodologies of two literacy research projects conducted in Sápmi, ${ }^{1}$ the traditional settlement area of the Sámi people in northernmost Europe. The chapter claims that awareness and respect of Indigenous research principles opens a door to understanding the context through inclusion, thus making the insider perspective possible. Such an understanding is crucial in order for researchers to see and recognize local

(C) HANNA OUTAKOSKI, 2021 | DOI: 10.1163/9789004463097_005

This is an open access chapter distributed under the terms of the CC BY 4.0 License. 
literacies, challenges, and successful approaches to the integration of literacy knowledges. Inclusion entails both the acceptance of the local perspectives in the research agenda, and all collaborations that obligate the researcher to constant introspection so as to assure that the main motivation and motives for the research originate from an appropriate source. I believe that these steps make it possible to explore what Indigenous methodologies and methods might entail within the field of educational literacy research.

Although this chapter takes up the opportunity of positioning Sámi writing and literacy research as an important factor in democratic societal development, the main aim of this chapter is to critically examine and compare the methodological choices of two Sámi projects. This is to see how literacy research can and should be developed in Sápmi, as well as in other Indigenous contexts (see also Chapter 7). A comparative introspective study like this is motivated by the seeming lack of Indigenous methodologies in the literacy field, and by a rising interest in including local literacies in Indigenous literacy research. It is still not clear what the Indigenous methodologies in this field can and should be, but close examination of already conducted projects can certainly highlight a number of areas within methodological choices that have the best potential for positive change.

In the analysis and in my conclusions, I have been especially inspired by Shawn Wilson (2001, 177), who argues that Indigenous methodologies are primarily about relational accountability. In its simplest form it means that the researcher is responsible and accountable for nurturing all relations with the community, including the research topic and other matters. According to Wilson, research methodology is about deciding how to use "your ways of thinking (epistemology) to gain more knowledge about your reality" (2001, 175). For me, finding this thought process has been challenging since explicit Indigenous methodologies are currently absent from literacy studies. It has made it harder to reflect upon whose reality it is that I am exploring. Is it the reality that I interpret through a research process, or is there another way of understanding the reality of the learners and their teachers by changing some aspect of the methodology? This chapter is part of that thought process, although I focus on the implementation of Indigenous Research Principles rather than on explicit methodologies. I believe these principles are the engine behind methodologies that are born and created by the inclusion of the Indigenous community in the research project.

This chapter is inspired by the ideas and questions that arose at the meetings of the international research network for Indigenous research methods in [Nordic] academia in 2017 and 2018, which I attended since the network began. The same network stands behind this book. The main goal of this network 
has been to bring together Nordic Indigenous and non-Indigenous researchers from the disciplines of arts, humanities, and social studies. The members of the network set out to examine collectively how the different disciplines approach Indigenous issues, and how Indigenous research methodologies and ethics can become a part of Nordic academia in Europe.

For me, joining the network has been an eye-opening experience. It has become very clear to me that my field, educational literacy studies, has until now offered very little room for Indigenous research principles and methodologies, although many studies have been conducted in minority and Indigenous contexts. More surprisingly, even some of the most prominent researchers within Indigenous studies and epistemologies have suggested to me that my field is insignificant in terms of implementing Indigenous methodologies. Such conversations have also taken place during the network meetings. The exclusion of literacy studies as a possible site for implementing Indigenous methodologies tells me that for at least some researchers Indigenous methodologies still represent something static, unchangeable and non-applicable outside the study of Indigenous epistemologies. For them, Indigenous methodologies are obviously not an active thought process of the kind Shawn Wilson referred to.

It is a tricky business to chase after traces of Indigenous methodologies or sites where such methodologies could be found within a field of study known not to apply and implement such methodologies. It is especially difficult when literacy, writing and texts are not included in traditional knowledges of the Indigenous people. In Indigenous research literature, writing is often viewed as a part of the research process rather than as an interesting site of Indigenous knowledge itself. Linda Tuhiwai Smith, for example, characterizes writing and literacy as something that "[...] has been used to determine the breaks between the past and the present, the beginning of history and the development of theory" $(2012,30)$. Smith also states that writing is still intimidating for many Indigenous students, and the way writing has been used in academia has also been a powerful way to silence Indigenous voices (Smith 1999/2012, 30). The experiences of colonial writing blur the development of Indigenous literacies, and the view still seems to exist that literacy, writing, and texts are extraneous to Indigenous contexts, and therefore are separate from Indigenous epistemologies and worldviews. This entails an understanding of texts and literacies as something definable and Western, and local literacies and texts are often excluded from these kinds of definition. In Indigenous contexts in general, writing is seldom seen as a basic human right, a means of self-expression, or a mediator of multiple identities, and is instead seen as an externally imposed educational mechanism that strengthens unequal power relations. The bitter memories of having to learn to read and write in a 
non-native majority language, the painful loss of the mother tongue, and ideologies that view the heritage language as less valuable than other languages, add to the way Sámi and other Indigenous people view writing in their own language. All these reasons why other researchers might see literacy studies as irrelevant are for me an urgent motivation to study this field. These revelations and experiences have motivated me to write this chapter, and to examine through critical introspection my double roles as a literacy researcher and a member of the Sámi community.

This chapter is organized as follows. The following section discusses the relevance of Indigenous literacy research in an era of linguistic imbalance in modern multilingual societies. It claims that the inclusion of Indigenous literacies in educational programmes as well as in the research agenda supports local societal development. The third section describes briefly some general and some local Sámi perspectives on writing so as to set the scene for the following section, which is a comparison of two Sámi literacy projects. The comparative section asserts that there are research topics and methods that belong to traditional literacy methodology, and that they can be a necessary step on the way towards a holistic understanding of the situation. At the same time, this analytical section also claims that respecting Indigenous research principles in literacy projects can have a significant effect on linguistic and cultural revitalization, and can open up space for the inclusion of local Indigenous methodologies. The final section provides concluding remarks claiming in harmony with much Indigenous research literature that the will and motivation to include Indigenous research principles in literacy studies is the first deliberate step in moving towards what can be characterized as Indigenous research and methodologies.

\section{Indigenous Literacies Support Indigenous Societal Development}

One of the many ways in which Indigenous peoples around the world are still affected by colonization and oppression has to do with a lack of opportunities for societal development. Indigenous societal development includes the establishment of a local societal infrastructure that values and promotes the Indigenous culture, the local environment, and the language of the people. The infrastructure then creates work opportunities, and can function as the main engine in linguistic and cultural development. However, current Indigenous societal development faces many obstacles and challenges that are to a great extent dependent on language policies, educational policies, and other state-level decisions on how to control and maintain power over all state affairs, Indigenous affairs included. 
In Botswana, for example, the San people are being kept away from the societal development of the rest of Botswana due to the unequal and disadvantageous educational policy that promotes English and larger domestic languages, and excludes local literacies (Ketsitlile et al. 2013). State policies thus push certain groups of people back, while others are promoted. In Hawai'i, the policies that in the past had as their main goal to annihilate all other forms of cultures and languages than English from local linguistic contexts have been removed. However, although language revitalization is a successful process on the larger islands, many native speakers in the most remote areas on the outermost islands are unable to read and write their own mother tongue. In these remote areas, native language has until now played almost no role in education. In these remote contexts, there seems to be a very clear divide between the spoken regional and local language, and written and official English. A positive development on the outermost islands involves the initiation of a new teacher training programme that takes native language, values, and ways of doing as the base for education (Faria et al. 2018). These programmes are important and witness how native Hawaiian has survived in small pockets in places where the state policies were not fully carried out. It is also in these environments that societal revitalization is now gathering strength to support the wider revitalization process. In the Sámi context, although oppressive policies have been actively counteracted and to a certain extent also removed, history is still a daily reminder of injustice. According to Johan Vasara, the welcome speaker at the World Indigenous Research and Education Conference (WIREC) 2018 and the former mayor of the strong Sámi language nest, Guovdageaidnu, written Sámi is almost entirely absent from the daily lives of the municipality workers. This reflects the situation elsewhere in Sápmi, where written Sámi is almost completely invisible in people's everyday lives, although it still seems to survive in academic and educational settings. In Sápmi, linguistic ideologies within the Sámi community have an impact on people's writing choices (Outakoski 2015a). Although officials, teachers, parents, and the learners themselves may value Sámi language and culture, real life practices may still promote the use of other languages in writing and in written communication.

In this chapter, I approach writing research from the Indigenous perspective, acknowledging the struggles that my fellow teachers and researchers experience in other Indigenous contexts. For now, I focus on the situation in Sápmi and, particularly, on two studies that have been carried out among Sámi learners and teachers. The power relations in Sápmi, the educational systems, political decisions, state policies, municipal policies, and all underlying beliefs and perceptions of languages have created a very complex situation in which the Sámi are in an inferior position (Outakoski 2015b). Nevertheless, I 
suggest that Sámi is no more written or oral than other languages, for it is not the language itself that carries such values as superiority or inferiority. Sámi is like any other language, and it has the potential to be anything or everything that other languages are. I also suggest that it is possible to have a positive effect on societal development and revitalization through research efforts that strengthen Indigenous literacy in the local community. In my view, promoting literacy does not mean cutting oneself off from some other cultural or linguistic domain, or contrasting literacy with oracy or traditional knowledge. Instead, promoting people's literacy in their Indigenous heritage language has an enriching effect on all areas of their linguistic and cultural knowledge.

\section{3}

\section{Positioning Writing}

All natural languages with the exception of sign language are primarily oral. It means among other things, and somewhat jokingly, that no humans are ever born with a pen in their hand. It is widely believed and asserted that people are somehow programmed or inclined to receive and look for information about how to code, interpret, and produce oral language. Depending on the theory (nativist, behavioural, or interactionist), the reasons for this inclination towards language learning vary, but all theories acknowledge the special period of early language learning. One could then say that humans are tuned in to receive and produce communicative messages between each other, and that a little child is especially alert in this process.

Establishing an oral language for children is important since children immediately and automatically start coding and interpreting the language they hear (e.g. Kuhl 2004). It is therefore sometimes said that a healthy child cannot consciously unlearn or hinder language acquisition (e.g. Radford 2004, 13). However, a child or an adult can forget parts of the language that are not in use. This is called language attrition or erosion (e.g. Köpke 2007; Ribes \& Llanes 2015; Riionheimo 2013). There are different levels of language attrition, or interruptions that depend on many things, mostly on opportunities to use and hear the language. Interruptions in the learning processes are especially disadvantageous for minority or Indigenous pupils, as they risk being deprived of a spectrum of reading and writing strategies that could aid them in meaning-making processes. Therefore, it is crucial for language revitalization that the child has continuous exposure to the threatened language. Oral language knowledge is also very valuable when the child or adult starts to learn to read and write. Oracy and oral language skills are thus important for the development of literacy. 
Alphabetical writing in its simplest form is the coding of sounds into arbitrary signs and letters that together build larger units and concepts that carry meaning or syntactic functions in the specific cultural and linguistic context they originate from. The child or adult then learns to build even larger units that carry propositions about the world, and that are used for meaning making, just as we do when we speak. Although oral language knowledge guides learners in their efforts to produce writing, it is not a natural process in the same way as first language oral acquisition is. The arbitrariness of the signs, letters and words creates the biggest differences between different languages. Learning the connections between signs and sounds, and how they are used to make meaning takes time. There are further differences between languages that base their writing on alphabets and sounds, as opposed to those that base their writing systems on symbols and combinations of signs. Yet we seem to have a strong tendency to learn the principals of these systems if we are given the necessary learning opportunities.

At the same time as we learn a language, we are building our understanding of the world and our understanding of pragmatics, that is, how to use the language we learn. For any pupil or student, Indigenous or non-Indigenous, natural language acquisition or learning is combined with the fine tuning of motoric skills, training of the memory, understanding the culture in which the language is spoken, and training social and communicative skills. The complexity of both the spoken and the written language increases as children or adult learners advance, receive instruction, test their knowledge, and most importantly, exercise their linguistic knowledge continuously and in a versatile manner.

Earlier research has shown that a number of linguistic strategies can be transferred between languages (Lindgren et al. 2016), and that knowing many languages opens up a spectrum of possibilities to construct complex Indigenous identities (Outakoski 2014). This is good news for all learners, as it means that reading and writing in any language brings advantages. Through reading, people widen their intellectual perspectives and build an ever-expanding lexicon. Through writing, people learn to express their thoughts in a controlled form, and learn to plan and organize their ideas and views. In addition to this, an open and welcoming language community also promotes participation in the local oral culture. The ability to participate in discussions and conversations promotes the use of languages in everyday life, strengthening the feeling of belonging and rootedness among the speakers. The ability to use one's own language, regardless of whether it is identified as the first language or the heritage language, gives people an opportunity to participate in societal development and societal meaning making in all situations in life. Through 
participation, acts of Indigenous citizenship become an important motor for societal revitalization.

\subsection{Writing in Sápmi}

Sámi literary history goes back to the seventeenth century when the church played an important role in the production of texts in Sámi. Before and during the first half of the twentieth century, in the time of oppressive and assimilative policies, only a few Sámi writers published texts in Sámi. Literature from this time ranged between a few longer books on Sámi traditional livelihoods, short fictional stories, poems, political pamphlets, and educational materials. Some of the rich oral tradition has been restored in writing, but accounts of other local Sámi literacies are scarce. The first positive turn in the Sámi literary field coincided with the birth of the Indigenous movement /in the late 196os/ in the beginning of the 1970s.

In the most recent report from the Sámi literary field, Johanna Domokos estimates that around 150 active Sámi writers presently produce texts in different Sámi languages and in other languages (Domokos 2018, 14). The professional Sámi writer society is rather small but is still proportional to the number of active Sámi speakers, which is at most around 10,000-30,000 people (see e.g. Outakoski 2015b, 7). Many writers from the 197os have remained productive over the years, and have regularly experimented with genres and changing readerships. From the beginning of this century, there has been a steady stream of new authors who have entered the Sámi literary scene. It is no longer easy to discern clear themes in Sámi literature, though it can be said that Sámi literature reflects the spirit of the Sámi community, and discusses central domestic, social, popular, and political themes that are present in the Sámi context at different times (Lill Tove Fredriksen, personal communication October 2018).

Of course, literature and artistic written expression are not the only writing that exists in Sápmi. Writing is often present in most occupations in some way. Reporters, journalists, and other media workers often depend on written manuscripts, and need quite advanced writing skills to match the requirements of the genres they work within. There is also a fair amount of academic writing produced in Sámi languages in the last couple of decades, and at least two academic journals that publish in Sámi languages have been established. ${ }^{2}$ Researchers, teachers, and people who produce teaching materials and academic articles need good writing skills. There are also new arenas created for Sámi literacy in the Internet, where language and visual contents are connected to form strong messages about the society, the political situation, environmental threats, and other urgent issues within the Indigenous community (see, for example, the community pages for the Sámi activist group 
Suohpanterror ${ }^{3}$ ). Community-based language projects in the social media and the Internet have also opened up new arenas for groups of writers and language activists (Outakoski et al. 2018). These new arenas can hopefully create space for local literacies and texts that have not been seen as part of the literary tradition before.

Many service occupations also require at least some writing skills. Municipalities with Sámi residents should, at least in principle, see that the information is also disseminated in Sámi. Although bilingual writers should be at an advantage in these situations, it is often the case that writing in the majority language is enough for occupational purposes, and most Sámi-speaking people do not write in Sámi in their daily lives, either at work or during their free time.

Currently, many Sámi lack formal writing skills in their own language mainly because of the colonising and assimilating goals and policies of the states that have subsumed the Sámi people, their lands, and their culture. Many people also lack writing skills in Sámi since, according to the underlying hegemonic ideology of majority vs. minority languages, literacy in the Indigenous heritage language is not viewed in the same way as it is in the majority language. In this respect, the Sámi share the same oppressive educational history as most Indigenous people around the world. Among Indigenous groups and other minorities, schooling has been a very powerful way to forcibly detach them from their own people's values, epistemologies, language, and culture (Minde 2003; Kuokkanen 2007). Social, economic, and political power has been, and still is, tightly connected to the symbolic function of the dominant language (Mæhlum et al. 2008,168 ). The nationalist ideas of an official state language are still in force in the Nordic countries, and most Sámi children still follow an educational trajectory where languages other than Sámi dominate the linguistic landscape of the school (Outakoski 2015a; Linkola 2014; Linkola \& Keskitalo 2015).

For the last four or five generations, most Sámi over the age of six have learned to read and write, thus becoming literate. Nevertheless, they may totally lack writing and reading skills in Sámi, which can be either their mother tongue and/or their heritage language. Elderly Sámi have also received some basic literacy training in schools in the Nordic countries, where basic education has been provided at an early age to all citizens. However, the learning process has often been limited to majority languages, and, for the younger generations, also to English and other foreign languages. When a Sámi without any formal education in Sámi language compares his or her writing skills in different languages, it is easy to spot the differences. This is then sometimes mistakenly interpreted as Sámi analphabetism, a common misperception among the Sámi themselves. When learning about schooling in the Nordic countries and about the history of Sámi writing, it is clear that, unlike some other remaining 
Indigenous peoples, the Sámi are not analphabets, they simply lack the opportunities for extensive writing training in Sámi.

Even if a person has learned to read and write Sámi, the pedagogy and didactics of literacy training are, in most Sámi schools, based on the didactic models designed for majority languages. The main reason for this, I would say, is that the development of Indigenous and Sámi didactics is still only at an early stage, and the current teacher training programmes have not as yet addressed Sámi writing didactics as a separate area in need of development. Endangered Indigenous languages also face the dilemma of having to sort out priorities concerning language revitalization. When a language has nearly been lost, the remaining speakers often feel that it is necessary to recreate the lost generations first, and to concentrate upon the oral language learning in the first part of the revitalization process (Olthuis et al. 2013; see also Chapter 7).

Few academic studies have examined the state of writing in Sápmi, although it is clear that there is a need to strengthen Sámi writing at all societal levels and sectors in order to reach cultural and linguistic development and balance. Most of the earlier research has concentrated on different aspects of Sámi literature, its contents, themes, writers, and other characteristic traits of Sámi artistic writing (e.g. Gaski 1987; Hirvonen 2008; Fredriksen 2015; Ahvenjärvi 2017). There are also linguistic studies of Sámi writing concerning, for example, accuracy (Antonsen 2013; Länsman 2009), and a number of studies concerning language technology, proofing tools, grammar checkers, and other technological writing aids for Sámi languages (e.g. Antonsen 2018; Wiechetek 2018). There are also a number of studies on Sámi education (Huss 2008; Keskitalo et al. 2011, 2012, 2014; Linkola 2014; Belancic et al. 2017), on Sámi teachers (RahkoRavantti 2016), and on curricula for Sámi education at different educational levels (Olsen et al. 2017; Belancic \& Lindgren 2017). It is very encouraging to see that after the turn of this century the Sámi educational sector has attracted a number of researchers, both Sámi and non-Sámi. Within the studies of writing and literacy in Sámi schools and in the educational sector, however, the studies are still very few and are concentrated in Umeå, Sweden. Many excellent and interesting studies on Indigenous literacy have been carried out internationally, but the main methodologies of literacy studies often belong to the tradition of ethnography, (critical) discourse analysis, literature studies, or experimental studies that use mixed-method approaches. To date, I have not found a literacy study that clearly states that it is primarily guided by Indigenous methodologies and thought processes.

Although this section has diverted us from the methodological focus promised in the beginning of the chapter, this section is necessary for Sámi readers. It is, to my knowledge, the first attempt to summarize the current and the past 
state of Sámi literacy, especially from an educational point of view. It is also a way to set the scene for the literacy studies that are being or will be conducted in Sápmi. In the following section, I will take a closer look at the methodologies of two literacy projects which I have worked with in Umeå, Sweden. Neither of the two studies have used Indigenous methodologies as their main methodologies. It is therefore not possible to compare or highlight such methodologies in this chapter. However, both studies have had as their main goal to conduct ethical research among Indigenous peoples with the aspiration of having a positive effect on the participating community. The comparison given in the following section is based on application and implementation of a number of Indigenous research principles in the two projects, as it is my strong conviction that an awareness of and respect for such principles is the first step to open up the field for new methodologies.

Multilingualism, Revitalization and Literacy Development: A Comparative Study

In the following sections, I first describe the two studies for comparison purposes. I then introduce the framework for guiding principles that I have used in my comparative analysis. Finally, I provide the reader with a comparative analysis of the two projects.

The aim of this comparison is not to assess the organization of the projects, or their results, and methods. Instead, the aim is to see to what extent Indigenous research principles have been respected and followed in educational Sámi literacy research in two specific cases. The term methodology in this chapter includes all choices and phases of the project from applying for funds to fieldwork and dissemination, and the decisions and choices made about methods for data gathering, analysis, and knowledge sharing.

\subsection{The Projects}

The first project was an internationally conducted study on writing and its contexts among young multilingual Sámi learners called Literacy in Sápmi: multilingualism, revitalization and literacy development in the global North. It was a three-year project running between 2012 and 2014. We used a mixedmethod approach both when we gathered and when we analysed the data from Finnish, Norwegian and Swedish Sápmi. The main data consisted of 832 texts written by 149 Sámi learners, 24 semi-structured teacher interviews, and 184 detailed questionnaires from pupils, parents, teachers, and principals. The 
research team arranged writing sessions at the schools, but did not otherwise participate in the activities, teaching, or lessons. The members of the school community who took part in the study were mainly seen as participants or informants, with very few opportunities to control any phase of the research project, or to access or own the data. The texts and the materials gathered from the schools were not returned to the writers, nor did the schools or the writers have access to the data that they had provided. The visits at each school lasted between three days to one week, making it a cross-sectional study.

All in all, the first project could be characterized as a very typical academic project that included a short visit in the community for the purposes of data gathering, but that otherwise was focused on academic goals and publications. Most of the published articles, book chapters, and other publications were written in English or Swedish, and only one academic paper was written in North Sámi. Although the research team hoped to arrange a dissemination tour to all the schools, the only active reach back to the community was a doctoral thesis (Outakoski 2015b) that was posted to all the participating schools. This thesis was written almost wholly in English, and I was the writer of the thesis. As an Indigenous doctoral student, I was never offered a possibility to write my thesis in my mother tongue, Sámi, but I was expected to write a thesis that was accessible to the English-speaking academic community and nonSámi members of the thesis committee. The research team did not produce any non-scientific publications in North Sámi that could have been read by the participants, the teachers, pupils' guardians, or the school principals.

A lot could be said about the first project when looked at from the Indigenous perspective, and the research team itself has also written a paper that discusses some of the pros and cons of the first project concerning the Indigenous research agenda (Outakoski et al. 2019). However, I always felt that the study we did was very valuable for the Sámi as well as for academia. It was the first large-scale literacy study among Sámi learners, and it provided the kind of results that are expected in a study that was a blend of positivist and sociocultural perspectives and methodologies. Among other things, the first study provided evidence on how the learners and teachers felt, and what they thought their writing environment looked like, i.e. their meta-pragmatic knowledge of the situation. This, however, could not reveal very much about actual longterm writing practices and discourses that surround learners at schools with Sámi pupils. The knowledge gap left behind by the first project was the main motivation for the second study. Without the insights from the first study, the second study would have lacked motivation and foundation, and it would have been difficult to offer solid arguments for funding. 
The second study was a postdoctoral research project that explored how teaching supports writing in a multilingual heritage language context. The how perspective of the project allowed for early negotiations and planning together with the community and participating institutions who were important research partners, rather than being merely informants. This was a 27-month study with a research period that spanned from August 2017 until December 2020. The project focused on the writing instruction and writing discourses in Sámi teacher training programmes, and at one primary school, where Sámi was used as the medium of instruction for most of the pupils. The research focus thus shifted from the learners in the first study to the learning environment and to teaching in the second study. The focus of the second study was on the discourses of writing that are present in an educational and Indigenous writing context, and the analysis was based on Ivaničs (2004) framework on language views, contexts, and discourses for writing. Although the project had a number of academic goals connected to the fact that the project was funded with a view to producing academic publications, one of the main aims of the study was to provide the community with models, means, and materials that could be directly used to strengthen writing instruction in teacher training and in schools. For this reason, I worked in the project as a part of the staff at the host institutions, and as a resource teacher in the school. My first task was to observe and to learn, and then to provide practical and theoretical support during the visiting period and after.

One of the ways in which I have changed my thinking process has to do with how I used my time in the project for the good of the community. As an example, one of the first things I did was to design writing workshops for pupils and parents at the school where I stayed for a year. During these workshops, four known Sámi writers visited the school and inspired the children to consider occupations where their Sámi skills are seen as an asset. I wrote an application for external funding for this part of the project, including purchasing computers and paying the visitors a fee. The project received funding from the local state government, and the municipality owned that part of the project. In this way the computers and further purchases, as well as other economic benefits, stay in the community and can be reused in similar motivational projects. It is clear to me that we researchers could do many more similar things for the communities for whom and with whom we conduct our research. For example, we have the skills to write applications for funding that are crucial for community internal development projects. In my case, every part of the project was carefully designed in cooperation with the schools and the municipality, and was directly connected to the phenomena that I am also interested in academically. 
Both projects have been conducted in a Swedish academic context, since the research is based in Umeå. The second study on writing discourses was shared with four participating host universities and one municipality in the northernmost part of Sápmi. The host universities for the international postdoc study were The Arctic University of Norway and Sámi Allaskuvla [Sámi University of Applied Sciences] in Norway, and Oulu University, and the University of Lapland in Finland. Both studies were primarily funded by the Swedish Research Council, and the second project was also co-funded by the Umeå School of Education. I was primarily responsible for establishing contacts with the research partners and for the planning and execution of the practical fieldwork in both studies, giving me a ground-eye view of the chosen methodologies. Most of the data collection methods and analysis methods in both projects are best described as traditional Western methods of inquiry. Thus, it is in the area of the actual working and analysis methods that I see a great need for development in the future if the research is to be characterized as Indigenous research.

\section{Framework for My Projects' Guiding Principles}

The comparisons presented later in this section are made using a number of leading principles for Indigenous methodologies that have been compiled from sources that the network for Indigenous research methods in academia has used as the basis for discussions and presentations during 2017-2018. The sources for principles thus vary from Indigenous research literature (e.g. Kovach 2009; Kuokkanen 2009; Smith 1999/2012) to principles endorsed by local Indigenous communities around the world.

Since there are a vast number of principles, some very general and others very detailed, I have made a selection of ten principles that reflect the current state of guiding ideas and structures within Indigenous research, as I have perceived them. I have also added an eleventh principle that is commonly discussed in research ethics in academia, namely recognition/honouring. These principles also reflect the discussions that we have had in the network. My intention is not to discard, or in any way disrespect my fellow researchers by making this selection and not a different one. The selection is a carefully thought out way to include academic as well as Indigenous community principles in my analysis that inevitably cannot consider each and every principle that has been formulated for Indigenous research methodologies. I am aware that the subjective selection will inevitably form and restrict my analysis, as would any other selection. 
First, I include the four main principles from the First Nations Information Governance Centre that are known as the OCAP principles (First Nations Information Governance Centre 2014, 5):

1. Ownership, which states that "[...] the community or group owns information collectively in the same way that an individual owns his or her personal information",

2. Control, which states that Indigenous "[...] people, their communities and representative bodies must control how information about them is collected, used and disclosed",

3. Access, meaning that the Indigenous community "must have access to the information and data about themselves", and that the community has the right to "manage and make decisions regarding who can access their collective information", and finally

4. Possession, which "is the mechanism to assert and protect ownership and control".

These four principles highlight the concerns of Indigenous peoples, concerning the organization, execution, dissemination, access, preservation, and sharing of the phases, data and results of research projects that target Indigenous matters, languages, cultures, knowledges, and identity. These perspectives are less easily discarded if the research is done in cooperation with the Indigenous community, and even more preferably, partly or fully by the members of such communities. Ten years before this chapter was written, Rauna Kuokkanen $\left(2009,143^{-144)}\right.$ wrote that it was time to concretize the work on research principles concerning research done in Sápmi, and about issues that concern the Sámi people. She suggested, as many other Indigenous researchers have done, that such concretization processes should begin by answering questions on the researcher's role, the goals and purpose of the study, the topics, the relations to the community, whether the knowledge provided by the research partners will be shared, and so on. In the Sámi context, transnational common principles are not yet fully formulated, but several educational institutions are currently working on local principles.

In addition to the Indigenous community principles, I have also chosen six principles for Indigenous research that originate from Indigenous and non-Indigenous academia. These six principles come from a review article by Snow et al. (2016). The principles were developed mainly for the purposes of qualitative and critical research, and are based mainly on the works of Hsia (2006), Lavallée (2009), and Smith (1999/2012). The principles from the Snow et al. (2016) review are:

5. Indigenous identity development, which "involves active renegotiation of one's cultural identity to accommodate understanding how colonization has influenced personal identity of self and others" (p. 362), 
6. An Indigenous paradigmatic lens, which "refers to using research approaches congruent with indigenous values and research goals" (p. 363),

7. Reflexivity and power sharing, which "is an interdependent process requiring focused attention to intrapersonal and interpersonal relationship dynamics before, during, and after the research process" (p. 364),

8. Critical immersion which "involves several interdependent elements to accommodate for privileging indigenous knowledge: empathy, active reflection, and the re-experiencing of a culture" (p. 365),

9. Participation and accountability, which "involves researchers, based on personal and professional commitments to conduct ethical research, empowering individuals and communities to engage in all aspects of the research process" (p. 366), and

10. Methodological flexibility, which "refers to researchers engaging in a variety of roles and using several 'alternative' data collection, analysis and presentation techniques congruent with indigenous ways" (p. 368).

The last principle has been added by me, but is well known from research ethics within Western as well as Indigenous research:

11. Recognition/honouring.

Within this principle I include recognition and honouring of the knowledge sources and knowledge processes that take place during, for example, a school literacy project in which the researcher is invited to the school in some specific role.

\subsection{Analysis}

A summary of my analysis is presented in Table 4.1. The white boxes illustrate a positive case where an Indigenous research principle has been used as a guiding principle throughout the study, the light grey boxes indicate successful consideration of the research principles, the darker grey boxes illustrate which principles have been less well implemented, and the darkest boxes exemplify principles that have not been considered or actively implemented at all.

The table shows very effectively where the weaknesses of the two literacy projects lie. The first observation from the analysis results is related to the research perspective. The darkest boxes in both projects are at the top of the table, where community-endorsed OcAP principles are found. Table 4.1 shows that the principles of Control, Access and Possession are those that have been most difficult to implement or to consider in both studies. The progress in this area is marginal, but the design of the second study has created space for active considerations, negotiations, and adjustments that give more control and better access to the community. As research projects, the two studies are never totally free from the requirements, expectations, and demands put on 
TABLE 4.1 Summary of the analysis of the implementation of 11 guiding principles on two adjacent and related literacy studies in Sápmi. The darker the colour of the box, the less successfully has the principle been considered and implemented in the project. The white boxes indicate that the principle has been actively implemented throughout the study

Guiding $\quad$ Project 1
principles

\begin{tabular}{l|l}
\hline 1. Ownership & Not actively considered in the project. \\
\hline 2. Control & $\begin{array}{l}\text { Not actively considered, and no control is given to the community. Motivation for the } \\
\text { project and description of the methods are explained in the information materials. The } \\
\text { research team has full control of the data. }\end{array}$ \\
\hline 3. Access & $\begin{array}{l}\text { Not actively considered. Some of the data is not accessible for ethical considerations, nor } \\
\text { can the community make any decisions about the future use or deletion of the data. Most } \\
\text { of the publications are not directly accessible to the community due to language choices } \\
\text { or for reasons to do with the publishers and their } \\
\text { publication policies. }\end{array}$
\end{tabular}

4. Possession $\quad$ No official assertions on community ownership or control were made in this project.

\begin{tabular}{ll}
$\begin{array}{l}\text { 5. Indigenous } \\
\text { identity } \\
\text { development }\end{array}$ & $\begin{array}{l}\text { No active renegotiation. These issues are partly dealt with in a method paper published after } \\
\text { the project. In an attempt to accommodate understanding, the results include analysis of } \\
\text { Indigenous identity expressions in the texts. }\end{array}$ \\
\hline $\begin{array}{l}\text { 6. Indigenous } \\
\text { paradigmatic } \\
\text { lens }\end{array}$ & $\begin{array}{l}\text { This project exemplifies a Western academic research approach with the main goal of } \\
\text { publishing papers mainly for an academic readership. The project design allowed for } \\
\text { inclusion of cultural adaptations in the data gathering phase. }\end{array}$ \\
\hline $\begin{array}{l}\text { 7. Reflexivity and } \\
\text { power sharing }\end{array}$ & $\begin{array}{l}\text { Short-term relationships were created based mostly on the former contacts and cultural } \\
\text { and local knowledge of the Indigenous researcher in the team. There was no power } \\
\text { sharing although the schools steer the research period. }\end{array}$ \\
\hline $\begin{array}{l}\text { 8. Critical } \\
\text { immersion }\end{array}$ & $\begin{array}{l}\text { Close to non-existent, although empathy was included in the ethical principles when } \\
\text { conducting interviews. When working with the pupils in class, there were also some } \\
\text { adaptations to accommodate any negative feelings connected to writing and certain } \\
\text { writing topics. }\end{array}$ \\
\hline
\end{tabular}

9. Participation and A determination to conduct ethical research according to Indigenous research ethics. However, accountability this form of research has very little effect on the community and allows only a small amount of engagement that has been predefined by the research team (e.g. the possibility of arranging workshops at the schools). $\begin{aligned} & \text { 1o. Methodological } \\ & \text { flexibility }\end{aligned}$
$\begin{aligned} & \text { Only a few adaptations were made, such as the language choices in connection to writing tasks } \\ & \text { and interviews. }\end{aligned}$

11. Recognition and honouring 
Project 2

Ownership of the interviews and all materials produced in the project is shared with the participants.

Control and mutual organization have been built into the project design from the beginning, as the research partners have been able to decide upon these details together with the researcher before the project applied for funding. However, the initiator of the design has been the researcher.

Some of the access is restricted by the order or decision of the local ethical board. The individual participants have access to data concerning themselves (e.g. interview copies), giving them the choice of using the material as they wish. Some of the materials are co-produced with the community so that the community has parallel access to and ownership of the materials and can make future decisions about the use of the produced content without academic intervention. However, some articles and papers will be less accessible as they are in English.

Inclusion of another locally funded project in the research project has made it possible to formulate assertions about possession, control and ownership of information, materials, infrastructure and knowledge that benefit the community already during the field work period.

The project includes continuous negotiations and renegotiations with the partners. Such negotiations also include introspection and reflections on researcher identity. It has been easier to consider this aspect of the research as the study has had the cooperation of the Indigenous community and Indigenous educational institutions.

This project can be identified as a blended approach to research that

tries to find a way to include Indigenous values even when it is difficult, or when it contradicts the academic restrictions placed on the project. There is a strong preference for Indigenous research goals that bring benefits to the research partners. Some academic goals such as producing international papers in English are also included as a natural part of the academic project.

This has been the main guiding principle for the project even before applying for funds. The project started by establishing a common goal and a shared research plan with the research partners. Long-term relationships have been established, and they are being nurtured by continuous and respectful contact with the partners.

The inclusion of critical immersion has been the second most important guiding principle in the second project. However, as a researcher of Indigenous peoples, I would not want to call my involvement in the activities reexperiencing the culture. I would rather want to focus on being aware of the cultural context, and also trying to locate the potential distortions that my position as academic researcher might introduce into the situation.

A determination to conduct ethical research, although there are new challenges when the researcher is included in the community and in that way becomes part of the research itself. The goal of the research is to find ways to empower the community as a collective as well as its members as individuals. However, it is not possible to let the partners engage in all aspects of the research, without risking the reliability and validity of the study.

The research plan was written in such a way that the data collection, analysis and dissemination methods could be recognized by the funders and the ethical board. At the same time, the methods were flexible enough for the researcher to be able to adapt them according to a number of Indigenous research principles.

Both projects have acknowledged the sources of knowledge, and expressed respect and gratitude toward all the participants in the projects. However, the local ethical board in Sweden does not recognize or approve of the ways in which Indigenous communities honour the sources of knowledge, thus creating restrictions for the implementation of this principle. This information about the restrictions has been shared prior to the study with all participants, making them aware of the situation. 
them by the funders and the academic community. These requirements seem to have an impact especially on the research plan, design and forms of data collection that are expected to be 'scientifically' controlled. In the first study, those academic expectations and their fulfilment were prioritized:

Looking back and reflecting upon our research questions and our initial design it was apparent that these originated from an academic interest in phenomena observed in society generally, and that the methodology of the study is informed by the Western epistemological traditions/ perspectives. The research questions were devised and formulated by us, the research team, without discussion with the community of North Sámi speakers and learners, or the wider North Sámi Indigenous community. (Outakoski et al. 2019, 168-169)

In the second study, the reflections from the first study have led to a change in attitude and perspective, and to a will to give the research partners better control of and access to at least the data that concerns them as individuals or as a collective in the form of a team of teachers. However, the second study also fails to receive its initial design and research goals from the community, although members of the Sámi teacher community have been involved in the design.

Another dilemma that is attested in the analysis concerns the dissemination and production of materials, academic papers, book chapters, articles and other materials that come out of these projects. In order to reach other Indigenous communities around the world, the medium of information cannot be solely North Sámi. In order to satisfy the academic community as well as the funders, the study must be disseminated in a scientifically accepted and validated manner so that it reaches a wide public. But in order for the community to gain benefits from participation in the study, the information should be given in the local languages, and in a form that is readable and understandable without previous academic training in the field. Neither of the two literacy projects considered here has received separate funding for translation that would allow for production of the materials in local languages as well as in English and Swedish. It is obvious that the two projects have failed to consider all the three potential publics in their designs, although the second project still has a chance to make ideological and practical decisions about the medium, language, and form of the research products.

The third result of the analysis concerns time frames and relations. Both of the projects considered here are rather traditional as far as the basic time frames and design are concerned, and have thus been limited by predefined 
phases of initial funding application, data gathering period, data analysis, and final dissemination. Both projects were also limited in time: the first project lasted for three years and the second project lasted for 2 years and 3 months. For myself as a Sámi researcher, a time frame of this sort means that there are no guarantees that the relations that are built up will, or can, be nurtured in the long run, other than perhaps as personal friendships. Non-Indigenous researchers, who enter into the community as outsiders, will often face more extensive difficulties.

For Indigenous research, and especially for literacy research that seeks to develop Indigenous literacy, these time frames are too narrow since there are no guarantees that projects have follow-ups, although researchers frequently seek continued funding for such activities. Also, the way funding and its time frames work, it is a challenge to include the community in the pre-application phase, especially if a working relationship has not yet been established. It is more usual that the community is only contacted after the project has received funding, and at that point the research design might be unchangeable and already rigidified. In our projects this was the case with the first project. The timeframes and the design of the project were focused on getting textual data from multilingual writers, and the relations with the schools and school staff, the writers, and the guardians were not considered a primary concern at any point of the project. The schools were merely given a chance to participate in a writing study, with no primary ambition to build relations that would lead to continued cooperation. In a project like this, it is easy to see why the other seven principles might not also be implemented successfully, or rather, why implementing these principles was not seen as an important goal of the project. In the first project, the implementation of Indigenous research principles was mainly restricted to the first and second phase of the project. In the first phase, for example, the writing tasks were adjusted to better reflect the Sámi context, and all contact materials and questionnaires were translated into Sámi and other local languages. In the fieldwork phase, the schools could suggest times and classrooms for data collection, and the interviews were carried out in the language preferred by the participants. Also ethical considerations, such as informed consent and a chance to leave the study at any point, were carefully integrated into the design. The community and relations with the community were not considered in the two remaining phases of the project, although a doctoral thesis was sent to the schools at the end of the project. Apart from the linguistic and contextual adjustments, and the careful ethical considerations, the first study resembled a literacy study that could have been conducted in any educational environment. 
In the second project, the principles of Reflexivity and Power Sharing (7) and Critical Immersion (8) were chosen as guiding principles before the study applied for funding. This meant, for example, that relations with the potential research partners were established in advance of the application process. Most of the relations were established well in advance, and the community of research partners was gathered together to discuss what role they would want me, the main researcher, to take and what role they themselves would want to play in the mutual project. Also, the school, the principal, and school district leader were contacted well in advance before the application process. I as a member of the Sámi community had an advantage of knowing most of the school staff and my Sámi colleagues at the host universities before starting the project. Another advantage was my linguistic knowledge, since I could communicate in any of the five languages that my partners in the project spoke.

An initial design for the study was presented to the research partners, and they then had the chance to change and adjust it before the application. Most of the partners did not propose any changes, which suggests that the Sámi teacher community still sees research as something that comes from outside, and that is in a way static. It may also have been the case that the partners did not feel a need to change the design since the open how questions created space for flexibility, change of perspective, Indigenous ways of knowing and doing, and for mutual concrete benefits. From that moment on, the research partners, the community of Sámi teachers in higher education and in one primary school, played an active role in forming the project. I also found a way to prepare the school community for independent development projects after the research period was over by carefully documenting the action research part of the project. I have also made sure that the school and the municipality gain control of the infrastructure needed for future writing projects by applying for funds that stay within the municipality and that pay for the computers and other materials that are needed for replication of the writing project in the future. In this way the competence that the teachers gain through the project stays in the local learning environment, and can be used in multiple ways to develop Sámi literacy, even if there is no continuation of the project after the second project ends.

The eleventh principle of Recognition and Honouring is difficult to follow and fully implement in current research. This is mainly due to the fact that Indigenous research projects, at least in Sweden, are still being evaluated and assessed by ethical boards that have no Indigenous representatives or any experience in carrying out Indigenous research. In Umeå, the local ethical board that evaluated both of the discussed projects, is experienced in evaluating large quantitative medical studies, and uses the same principles 
in evaluating Indigenous research projects within the humanities and arts. It does not acknowledge individual or collective knowledge sources, which has led to a situation where all research participants and partners must remain anonymous. This contradicts the principles of Indigenous research ethics that merely see the researcher as a vessel for mediating the knowledge that originates from the community, and that reserves the ownership of the knowledge to its sources. It is clear that this aspect of research among Indigenous peoples has not developed in the direction it should in the Nordic countries, and much remains to be done in order to reach full implementation of the eleventh principle. The second project explored new ways to recognize knowledge sources, such as co-authoring papers and other materials. None of the projects is, however, anywhere near the satisfactory implementation of the last principle.

Although there are many areas that can be improved, the analysis shows that it is possible to shift from purely Western traditional research methodology toward a research methodology that also acknowledges, respects, and follows Indigenous research principles within literacy studies. There are still a number of challenges in finding appropriate methodologies for Indigenous literacy research, but there are a number of pioneers who are paving the way. Multiple research methodologies can also exist simultaneously, but for all literacy research carried out in Indigenous contexts, it is important to be aware of the choices one makes as a researcher. In Umeå, after our first Sámi literacy project, several new projects were initiated, and all of them show a new kind of awareness of Indigenous research principles.

\subsection{A Personal Note on the Analysis}

For me as a researcher it is somewhat disturbing not to know exactly where my project is headed epistemologically, since I only have previous experience from traditional Western studies within literacy and syntax. In the first study I was doctoral student, and a part of a team where much more experienced researchers were directing matters, relieving me from some of the academic, moral, and practical burdens of a large research project. But even if it was, and still is, daunting to step out there, I did not hesitate to take up the opportunity to design a new study. It was a great opportunity to learn more about how literacy research can be designed and formed using Indigenous research principles as a guiding light. It has been of value to sort out my own priorities, in life as well as in academia.

It is clear to me that literacy studies should always make space for methodologies that feed back into the community, which is one of the leading principles of Indigenous research. I also claim that conscious implementation of Indigenous research principles in literacy studies conducted in Sápmi encourages 
local societal and community development. Such development can, in the best scenario, have long-lasting positive effects on the revitalization of a threatened language and its mother culture. Thirdly, I suggest that not all research that benefits Indigenous peoples can be guided by all the principles that characterize Indigenous research. An example of this is the choice of research topic which, according to Indigenous research principles, should be chosen in consultation and cooperation with the community, or, if possible, the topics should originate from the community itself. This, however, can be difficult if the community is, for example, (mis)guided by hegemonic ideologies that exclude certain research topics in the first place (see more on the Sámi and hegemony in e.g. Kuokkanen 2007, 149-150). Thus, for example, if the community sees no value in writing in their heritage language, then for a literacy researcher it could mean that any research topics having to do with writing would be hard to approach when negotiating research ideas and specific questions with the community. Another problem could be that the researcher could be asked to study totally different aspects of education or local context than the areas in which she has research competence. Perhaps this is not so much of a problem for the community as it is for the researcher and the narrow research field she might represent. Nevertheless, in such a case, it might sometimes be better to approach the community with a flexible research plan or idea, and to openly negotiate the possible topics, execution of the project, and the goals of the project, rather than the individual research questions that could still be of detailed academic character. Inclusion of community members in the research team might also ensure that the important community internal questions and perspectives are not discarded. In my case, I had the advantage of belonging to the community, and of being able to adjust and fine-tune the project along the way as I gained more knowledge and insights about the local context.

There are new questions that have surfaced as a result of my engagement in the two projects, and after having written this chapter. For one, I firmly believe that in the future we need parallel discussions with the communities and with researchers who aim at doing Indigenous research, so that both sides become better aware of their potentially changed roles in the research. Second, I still do not know what Indigenous methods of data gathering and analysis might be most appropriate in the field of literacy studies. However, I am willing to experiment, and I believe that I have already seen examples of methods that I have not considered before. I am becoming aware of a silent mentorship that was created between myself and the teachers who I accompanied. Together we were talking about Sámi literacy, and in which ways it might differ from mainstream literacies. I was also listening to my pupils. Their language is not trapped on the pages of their school books, and their literacies come from 
different sources than mine. I am, moreover, actively learning more about these sources. Third, although research in Indigenous contexts should always have the goal of giving back to the community, the community might be in need of something else than just research. I have come to the conclusion that it is the responsibility of the researcher to seek out such needs, and, already in the planning phase of the project, to examine whether it is possible to include community development in the project. Such considerations make it easier to respect and follow Indigenous research principles.

There are also a huge number of moral and ethical challenges, questions, and dilemmas that I have only just started to process. One important thing that I somehow feel a need to explain is that the way I have conducted my research has not been a strategy to make the community feel indebted to me, but is instead a way to show goodwill and caring without selfish motives. In return, the teachers and the school staff have included me in their community without suspicion or doubt. Inclusion has not come without an effort on both sides, and I am forever thankful for the contributions that my research partners have made to the project. Our project builds upon mutual trust; it requires engagement, flexibility, knowledge of the local language and culture, and the desire and opportunity to nurture long-lasting relations. Through such inclusion I have gained invaluable and unique insights into Sámi literacy instruction, Sámi educational writing contexts, and myself as an Indigenous Sámi researcher. Without inclusion and all the phases that have led there, my insights would not have been so rich, complex, and multifaceted. Having said that, the same inclusion places me under a great amount of pressure. I know that I need to be a good researcher, a good friend, an ally, a guide, and an observer, all at the same time. No matter what methodologies we follow, the hardest thing to do is to accommodate all those roles in one.

\section{Summary}

After having spent over two years as a guest at Sámi higher education institutions and at one Sámi primary school, I have started to question my own role as a researcher in the development of Sámi education in practice. It has become very clear to me that Sámi teachers, pupils, and parents do not directly benefit from the literacy research that is done in the Nordic universities, since such research often only adds to the knowledge bank of the academic community without any direct benefits to the Indigenous community. More is needed of researchers and their chosen methodologies. If the methodologies result in the research being inaccessible to the communities, not duly respecting the 
sources of knowledge, and having no long-term real life impacts or having little practical effects on the literacy development of the people, then it cannot be categorized as Indigenous research.

Any research methodology that involves interactions with individuals and communities should include some sort of platform where the interests of the research field could be connected to the ideological and practical reality of the research participants and partners. Thus, bringing in new methodologies in literacy studies does not have to mean changing everything in the field. Instead, implementation of Indigenous methodologies in addition to Western methodologies can make the entire field witness and understand the effects of methodological choices for the local communities, whether they are Indigenous or not. Further, the inclusion of Indigenous ethics and methodologies in literacy studies can be an effective way to support societal development in Indigenous contexts. This is especially true if the research design includes activities or measures that provide direct benefits to the community already during the fieldwork period.

I have approached my field and its methodologies by looking at how two projects manage to acknowledge and respect eleven Indigenous research principles. If the most basic principles are not being considered, then it is very difficult to see how new methodologies can guide the field. I have found that perhaps the greatest challenge lies in opening up space for the communities' internal principles in research, whatever they may be in each context. This being said, it is also very clear to me that not all literacy research that is carried out among the Sámi should or can be categorized as Indigenous research. For example, without the first project presented in this chapter, a project which derives from the Western academic tradition, the second collaborative project would not have been possible or motivated. Moreover, the lessons learned from the second project will clearly be useful when arranging future cooperation in the field of literacy research.

The process of critical introspection has made it much clearer to me that respect for Indigenous research principles is only the first necessary step toward holistic Indigenous methodologies within literacy studies. A vision for such future research then includes a will and motivation to include and follow as many of the Indigenous research principles as is possible, thus deliberately moving towards what can be characterized as Indigenous research. While writing this chapter, I have also realized that I am already in a new thought process. It is the sort of process that Shawn Wilson (2001) was describing. My thoughts now focus on relations, listening, and accountability rather than doing research and finding answers. From here on I need a great deal more sensitive tuning so that the initiated thought process can form and inform my future research. 


\section{Acknowledgements}

I wish to thank and honour my colleagues and supervisors who worked with me in the first project, Literacy in Sápmi. The project was led by Professor Kirk Sullivan, and the research team also included Professor Eva Lindgren and Professor Asbjørg Westum. Most of the articles that have been produced in the first project are co-written by the research group. I also wish to thank my main supervisor Professor Mikael Vinka. The Swedish Research Council is the main funder of both projects Literacy in Sápmi (project 2011-6153, contract Bo615301) and How does teaching support writing in a multilingual heritage language context? (International Post Doc 2017-00474). The Umeå School of Education co-finances the second project. I want to thank both of the funders without whom these projects would not have been possible. I am also grateful for the encouraging comments from the two anonymous reviewers of this chapter. Most importantly, I want to thank and honour all of my research partners in both projects, without the approval and participation of the community there would not have been any research. Giitu!

\section{Notes}

1 See http://www.samer.se/karta for a map of Sápmi.

2 The two Sámi journals are Sámi dieđalaš áigečála (SDÁ) established in 1994 http://site.uit.no/ aigecala/ accessed 21 December 2018), and the newly-established Sámegiela ja -kultuvrra dutkansearvvi dieđalaš áigečála (http://dutkansearvi.fi/diedalas-almmuheapmi/ accessed 21 December 2018).

3 See https://suohpanterror.com/ (accessed 12 November 2018).

\section{References}

Ahvenjärvi, K. (2017). Päivitettyä perinnettä: Saamelaisen nykyrunouden saamelaiskuvastoja [Updated tradition: Sámi imagery in contemporary Sámi poetry] (PhD dissertation). University of Jyväskylä. Jyväskylä Studies in Humanities 318.

Antonsen, L. (2013). Čállinmeattáhusaid guorran [Tracking writing errors]. Sámi dieđalaš áigečála, 2, 7-32.

Antonsen, L. (2018). Sámegielaid modelleren - huksen ja heiveheapmi duohta giellamáilbmái [Modelling of Sámi languages - Contruction and adjustment for real life purposes] (PhD dissertation). UiT The Arctic University of Norway.

Belancic, K., \& Lindgren, E. (2017). Discourses of functional bilingualism in the Sami curriculum in Sweden. International Journal of Bilingual Education and Bilingualism, 1-16. https://doi.org/10.108o/13670050.2017.1396283 
Belancic, K., Lindgren, E., Outakoski, H., Westum, A., \& Sullivan, K. P. H. (2017). Nordsamiska i och utanför skolan: språkanvändning och attityder [North Sámi in and outside the school: Language usage and attitudes]. In M. Liliequist \& C. Cocq (Eds.), Samisk kamp: kulturförmedling och rättviserörelse [Sámi struggle: Culture mediation and justice movement] (pp. 252-279). Serie Akademi. H:ström.

Domokos, J. (2018). A writing hand reaches further "Čálli Giehta Ollá Guhkás": Recommendations for the improvement of the Sámi literary field (E-publication). Culture for All Service/Yhdenvertaisen kulttuurin puolesta ry.

https://multilingualmonth.files.wordpress.com/2018/10/writing_hand_reaches_ further_verkko.pdf

Faria, K., Kuuipo Wong, A., Pahulehua, L., \& Brun, N. (2018, August 23). He Aupuni Palapala Ko'u: Authentic text and experiences in Hawaiian language development. Paper presented at the WIREC (World Indigenous Research and Education Conference). Sámi allaskuvla, Guovdageaidnu [Kautokeino], Norway.

First Nations Information Governance Centre. (2014). Ownership, Control, Access and Possession (OCAPTM): The path to First Nations Information Governance. First Nations Information Governance Centre. https://achh.ca/wp-content/uploads/2018/o7/ OCAP_FNIGC.pdf

Fredriksen, L. (2015).... mun boađán sin mayis ja joatkkán guhkkelebbui ... Birgengoansttat Jovnna-Ánde Vesta románatrilogiijas Árbbolaččat [... I come after them and I continue even further ... Coping skills in Jovnna-Ánde-Vest's Árbbolaččat] (PhD dissertation). UiT The Arctic University of Norway.

Gaski, H. (1987). Med ord skal tyvene fordrives: om samenes episk poetiske diktning [With words shall the thiefs be banished: About the epic poetry among the Sámi]. Davvi Media.

Hirvonen, V. (2008). Voices from Sápmi: Sámi women's path to authorship (K. Anttonen, Trans.). DAT.

Hsia, H.-C. (2006). Empowering "foreign brides" and community through praxisoriented research. Societies without Borders, 1, 93-111.

Huss, L. (2008). Revitalization through Indigenous education: A forlorn hope? In N. H. Hornberger (Ed.), Can schools save Indigenous languages? Policy and practice on four continents (pp. 125-35). Palgrave Macmillan.

Ivanič, R. (2004). Discourses of writing and learning to write. Language and Education, 18(3), 220-245.

Keskitalo, P., Määttä K., \& Uusiautti, S. (2011). Toward practical framework of Sámi education. British Journal of Educational Research, 1(2), 84-106.

Keskitalo, P., Määttä K., \& Uusiautti, S. (2012). Sámi education in Finland. Early Child Development and Care, 182(3-4), 329-343.

Keskitalo, P., Määttä K., \& Uusiautti, S. (2014). “Language immersion Tepee” as a facilitator of Sámi language learning. Journal of Language, Identity \& Education, 13(1), 70-79. 
Ketsitlile, L. E., Bulawa, P., \& Kgathi, O. T. (2013). Transforming literacy research for the Indigenous San of Botswana: Adopting appropriate research methods. AlterNative: An International journal of Indigenous peoples, 9(1), 45-59.

Köpke, B. (Ed.). (2007). Language attrition: Theoretical perspectives. Benjamins.

Kovach, M. (2009). Indigenous methodologies: Characteristics, conversations, and contexts. University of Toronto Press.

Kuhl, P. K. (2004). Early language acquisition: Cracking the speech code. Nature Reviews Neuroscience, 5, 831-843.

Kuokkanen, R. (2007). Saamelaiset ja kolonialismin vaikutukset nykypäivänä [The Sámi and the consequences of colonialism in the present]. In J. Kuortti, M. Lehtonen, \& O. Löytty (Eds.), Kolonialismin jäljet: keskustat, periferiatja Suomi [The tracks of colonialism: Centers, peripehries and Finland] (pp. 142-155). Gaudeamus.

Kuokkanen, R. (2009). Boaris dego eana: Eamiálbmogiid diehtu, filosofiijat ja dutkan [Old as the Earth:Indigenous peoples'knowledge, philosophies andresearch]. ČálliidLágádus.

Länsman, O. (2009). Oahppiid feaillat čállosiin [Students' mistakes in texts]. In J. Ijäs \& N. Ø. Helander (Eds.), Sáhkavuoruin sáhkan: sámegielaja sámi girjjálašvuođa muhtin áigeguovdilis dutkanfáttát [From presentations to content: Some current research topics within Sámi languages and literature] (pp. 70-85). Dieđut. Sámi allaskuvla/ Sámi University College.

Lavallée, L. F. (2009). Practical application of an Indigenous research framework and two qualitative Indigenous research methods: Sharing circles and Anishnaabe symbol-based reflection. International Journal of Qualitative Methods, 8(1), 21-40.

Lindgren, E., Westum, A., Outakoski, H., \& Sullivan, K. P. H. (2016). Meaning-making across languages: A case study of three multilingual writers in Sápmi. International Journal of Multilingualism, 14(2), 124-143.

Linkola, I.-A. (2014). Saamelaisen koulun kielimaisema: Etnografinen tutkimus saamen kielestä toisen asteen oppilaitoksessa [Linguistic landscape of a Sámi school-Ethnographic study on the visibility of Sámi in upper secondary school] (PhD dissertation). University of Lapland. Dieđut 2.

Linkola, I.-A., \& Keskitalo, P. (2015). Sámegiela oinnolašvuohta sámi skuvllas [Visibility of Sámi language in Sámi school]. Sámi dieđalaš áigečála, 1, 7-28.

Mæhlum, B., Sandøy, H., Røyneland, U., \& Akselberg, G. (2008). Språkmøte: Innføring $i$ sosiolingvistikk [Language meeting: Introduction to sociolinguistics] (2nd ed.). Cappelen Akademisk Forlag.

Minde, H. (2003). Assimilation of the Sami: Implementation and consequences. Acta Borealia, 20, 121-146.

Olsen, T. A., Sollid, H., \& Johansen, Å. M. (2017). Kunnskap om samiske forhold som integrert del av lærerutdanningene [Knowledge on Sámi situation as an integrated part of teacher education]. Acta Didactica Norge, 11(2), Art. 5, 1-15.

https://doi.org/10.5617/adno.4353. 
Olthuis, M.-L., Kivelä, S., \& Skutnabb-Kangas, T. (2013). Revitalising Indigenous languages: How to recreate a lost generation (Linguistic diversity and language rights). Multilingual Matters.

Outakoski, H. (2014). Språkrikedom skapar ett mångsidigt identitetsspektrum [Multilingualism creates a versatile identity spectrum]. Kulturella Perspektiv, 23(1), 58-66.

Outakoski, H. (2015a). Davvisámegielat čálamáhtu konteaksta [The context of North Sámi literacy]. Sámi dieđalaš áigečála, 1, 29-59.

Outakoski, H. (2015b). Multilingual literacy among young learners of North Sámi: Contexts, complexity and writing in Sápmi ( $\mathrm{PhD}$ dissertation). Umeå University.

Outakoski, H., Cocq, C., \& Steggo, P. (2018). Strengthening Indigenous languages in the digital age: Social media-supported learning in Sápmi. Media International Australia, 169(1), 21-31.

Outakoski, H., Lindgren, E., Westum, A., \& Sullivan, K. P. H. (2019). Researching writing development to support language maintenance and revitalization: Design and methodological challenges. In C. Cocq \& K. P. H. Sullivan (Eds.), Perspectives on Indigenous writing and literacies (pp. 165-185). Brill.

Radford, A. (2004). Minimalist syntax: Exploring the structure of English. Cambridge University Press.

Rahko-Ravantti, R. (2016). Saamelaisopetus Suomessa: Tutkimus saamelaisopettajien opetustyöstä suomalaiskouluissa [Sámi education in Finland: Research on Sámi teachers' work in Finnish schools] (PhD dissertation). Acta Universitatis Lapponiensis 332. Lapin yliopistokustannus.

Ribes, Y., \& Llanes, À. (2015). First language attrition: The effects of acculturation to the host culture. Procedia - Social and Behavioral Sciences, 173, 181-185.

Riionheimo, H. (2013). Johdannoksi: Ensikielen attritiosta [For an introduction: First language attrition]. In K. Granqvist \& P. Rainò (Eds.), Rapautuva kieli: Kirjoituksia vähemmistökielen kulumisesta ja kadosta [Eroding language: Papers on erosion and loss of a minority language] (pp. 11-36). Finnish Literature Society.

Smith, L. T. (2012). Decolonizing methodologies: Research and Indigenous peoples (2nd ed.). Zed Books. (Original work published 1999)

Snow, K. C., Hays, D .G., Caliwagan, G., Ford, D. J., Mariotti, D. Maweu Mwendwa, J., \& Scott, W. E. (2016). Guiding principles for Indigenous research practices. Action Research, 14(4), 357-375.

Wiechetek, L. (2018). When grammar can't be trusted - Valency and semantic categories in North Sámi syntactic analysis and error detection (PhD dissertation). UiT The Arctic University of Norway.

Wilson, S. (2001). What Is Indigenous research methodology? Canadian Journal of Native Education, 25(1), 175-179. 